\title{
ASSESSING A DIGITALISED CITIZEN CONSULTATION PLATFORM BASED ON A QUALITATIVE SURVEY THE CASE OF VALAIS CANTON'S NEW CONSTITUTION
}

\author{
Emmanuel Fragnière ${ }^{1,2}$, Vincent Grèzes ${ }^{1}$, Martine Hofstädter ${ }^{1}$, Dominic Juon ${ }^{1}$, \\ Sherine Seppey ${ }^{1}$ and Randolf Ramseyer ${ }^{1}$ \\ ${ }^{1}$ HES-SO Valais-Wallis \\ ${ }^{2}$ University of Bath \\ Rue de la Plaine 2, 3960 Sierre, Switzerland
}

\begin{abstract}
The practice of citizens' democratic rights and duties must be questioned at a time when many of our daily customs and rituals are being challenged and redefined by the digital revolution. While retailing has already profoundly altered our daily interactions, any practice related to the exercise of democracy remains very traditional and this seems to be at the root of an ever-increasing disinterest in politics, especially among young people. We had the opportunity, through a qualitative survey, to study this theme in relation to the complete revision of the Constitution of the Canton of Valais in Switzerland. The latter follows a democratic process in which 130 citizens of Valais were elected to revise the Constitution. In addition, a consultation was put online on a platform as a pilot project from 7 November 2019 to 5 January 2020 with the aim of encouraging citizen participation and thus giving a voice to all the inhabitants of Valais. In this paper, we present the main elements of this qualitative survey based on the technique of "hypothetical scenarios", conducted among 20 Valais residents interested in politics (the majority of the interviewees did not use the online platform, a minority did, and some of the interviewees are "stakeholders" linked to the Constituent project). In addition to the survey based, we also carried out a "netnographic" analysis using the 1,235 contributions left on the platform during the pilot project period. The analysis of the transcripts made on the basis of the semi-directive interviews shows an interest in these digital citizen platforms. However, the respondents recognise that the citizens' platform is a first test and that more innovation and testing in this area is needed to involve people who are not currently participating in the democratic debate. This is somewhat confirmed by our netnography, as all the content of the platform has been produced by people with a proven political culture.
\end{abstract}

\section{KEYWORDS}

Citizens Participation, E-Democracy, Qualitative Survey, Digital Platform

\section{CONTEXT}

A digital consultation platform should make it possible to remove institutional and geographical borders and offer the greatest possible number of people the opportunity to participate in and contribute to the project for a total revision of the Valais Constitution. These new virtual discussion forums contribute to broadening the basis for participation by opening up a space for expression and dialogue for all inhabitants and by reducing spatial distances. These tools are particularly valuable in a peripheral mountainous region such as the canton of Valais in Switzerland, where the spatial heterogeneity between plain and mountain, medium-sized towns, isolated villages and hamlets is evident, and where, moreover, statistical indicators describe a highly contrasted socio-economic reality.

Within the framework of this research, we evaluated, through a qualitative survey, a digital platform for the canton of Valais, set up from 7 November 2019 to 5 January 2020, as a first phase of citizen participation aimed at gathering ideas, enriching the reflections of constituents and learning about the concerns of the general public, with the objective of including as many citizens as possible in the rewriting of the new cantonal constitution. Our targeted sampling strategy (Ghauri et al. 2005) integrates three categories of profiles:

1. People who have never used the platform

2. People who have used the platform. 
3. People who are directly or indirectly linked to the "Constituent Assembly".

Parallel to the fieldwork, a netnography (Kozinets, 2007) was also carried out on the basis of the contributions left (496 proposals, 731 arguments, 8 sources, in French and German) on the platform by mainly Valais citizens.

This research on digital citizen platforms has already started in 2018. It is part of a series of ethnographic studies (e.g. electronic voting) and research on the design of services linked to the notion of citizen pathways (e.g. augmented reality for simplified access to voting material) conducted by our Institute (ITO) on the broader theme of public e-governance.

In this report, we present the main results collected during the interviews as well as those from the netnographic analysis. The interviews were conducted in French and German, Valais being a bilingual canton, as well as in English to interview some expatriates living in Valais, the platform being open to all. On the basis of a diagnosis of these main results, we propose elements for the evaluation of the pilot project of the citizens' platform as well as recommendations for its improvement for future use. It should be noted that the digital citizen platform of the HES-SO Valais-Wallis is not intended solely for use by the Valais Constituent Assembly. In fact, it is presented as a "tool for digital democracy" which aims to inform, consult and involve the population in all major future projects in the Valais.

The current Constitution of the Canton of Valais came into force on 8 March 1907. The text begins with "In the name of God Almighty!" and its first article reads as follows: "Valais is a democratic republic, sovereign within the limits of the Federal Constitution and incorporated as a canton into the Swiss Confederation". On 4 March 2018, the people of Valais accepted the popular initiative for a total revision of the Cantonal Constitution and decided to entrust the work to a "Constituent Assembly". The election of the 130 members of the Constituent Assembly took place on Sunday, 25 November 2018. The Assembly is divided into thematic committees, including a Citizens' Participation Committee which proposed for a 1st phase of participation the use of a digital consultation platform: valaisdemain.ch and wallismorgen.ch on a trial basis for two months (7 November 2019 to 5 January 2020). This initiative was based on Article 32(2) of the Constituent Assembly, "the Commission [...] shall make available to the constituent body one or more models of citizen participation (digital platform, citizens' workshops, etc.) compatible with the general process of the Constitution's work, propose a timetable $[\ldots]$ and ensure the implementation of the model chosen".

The digital platform set up includes a consultation area divided into 10 sub-sections corresponding to the 10 thematic committees of the Constituent Assembly (which will a priori correspond to the 10 chapters of the new Constitution). These themes are subject to consultation, with the possibility for participants to make proposals, to add arguments for and against the proposals and to vote on the proposals. These spaces are administered directly by the citizens' platform. The raw results are then transmitted to the Constituent Assembly.

The objective of this research is first to generate hypotheses related to the use of this platform in terms of the involvement of the Valais population in the overall democratic process. At a later stage, this study also aims to improve the current platform in terms of its characteristics and user-friendliness.

This report is organized as follows. In Section 2, we present a review of the literature on the topic of digitized citizen participation. In Section 3, we explain the qualitative fieldwork approaches used in this research. In Section 4, we describe and discuss the main findings of our fieldwork (interviews and netnography conducted during the pilot phase of the project). In Section 5, we conclude and provide directions for further research.

\section{LITERATURE REVIEW}

The objective of this exploratory study is to better understand the innovations related to the mode of democratic process induced by digitization in our society through a brief review of the literature. In the field of democratic debate, the introduction of citizen platforms is gaining momentum. It is therefore crucial to consider the factors that will affect the acceptance of these systems by users. In general, for a technology to be successfully implemented, its performance must be oriented towards user acceptance. Thus, the Technology Acceptance Model maintains that two main beliefs influence an individual's behavioural intention to use a system: perceived usefulness and perceived ease of use (Venkatesh and Davis, 2000). People use a technology only when they perceive its usefulness. Perceived usability, on the other hand, refers to the extent to which an 
individual believes that a particular system can be used effortlessly (Davis, 1989). Venkatesh et al. (2003) propose the "Unified Theory of Acceptance and Use of Technology" (UTAUT). Their theory postulates three direct determinants of intent to use: performance expectation, effort expectation, and social impact. The precepts of this theory also clarify two direct determinants of actual use: the intention to use and the facilitating conditions (material and/or human conditions that facilitate the use of the product in question). In addition to the direct determinants, this model also examines moderating variables: previous experience with the system, whether use is voluntary or involuntary, gender and age. Collan F. et al. (2011) suggest that a user will most often adopt "lazy user behaviour" to satisfy his or her information needs by choosing the solution that requires the least amount of effort. For the authors, the choice of the solution is motivated by two main aspects which are the user's need and the user's condition. The user need is defined by the detailed information that the user requires and is characterized by factors such as urgency, nature of the need, complexity, etc., while the user state is contextualization and circumstances characterized by factors such as location and time. The user state limits the solutions available, such as devices, to satisfy the user's need. According to Callon (2009), social science studies identify actors (here users) as calculating agents pursuing their own interest by performing economic calculations in search of an optimisation and/or maximisation operation. This observation allowed Collan and Tétard (2011) to describe a process model of individual behaviour composed of four learning phases where the user must make a learning investment. The four learning processes are as follows: initial pre-use creating an expectation (belief) about the technology; first use where the expectation is compared to actual use; early use creating an early experience and its use over time; and then routine use corresponding to the cycle of adoption and learning. With the creation of citizen participation initiatives, participatory democracy is making its way into politics. Indeed, there is a growing desire to give more room to public opinion in the development of major public projects. However, citizen participation initiatives currently do not have the echo and impact that one might expect (democratic deficits in the political process) and therefore, according to Przeworski et al. (1999), do not allow for effective citizen participation in the decision-making process "if the difficulties or democratic deficits that prevent electoral institutions from making government responsive are not taken into account".

\section{METHODOLOGY}

In order to better understand the conditions of acceptance of the citizens' platform by citizens, we conducted a field research from November 2019 to January 2020 based on an ethnographic approach. Ethnography is the descriptive study of the activities of a particular human group. More specifically, we use "ethnomethodological" approaches that are not based on an a priori theoretical framework (in particular, cultural theory).

In practice, we rely on a cantonal field survey based on semi-directive interviews (twenty) in order to directly question the inhabitants of Valais about their positions, fears and hopes regarding the digital consultation platform; which was made available to citizens between 7 November 2019 and 5 January 2020 (this initiative is considered a pilot project). The analysis of the results, proposed in this report, allowed us to identify the latent needs of the target population, to identify social trends for the design and improvement of this type of e-participation platforms. The discussion (or diagnosis) of the analysis of the results then highlights the intangible elements that bring real added value to users. It is therefore a process of reflection that describes a reality of individuals through a precise context, their beliefs, their reactions and their functioning in the whole democratic system of which it is part.

Macintosh et al. (2008) noted that a number of qualitative methods are needed, which, moreover, are not only related to user satisfaction but rather determine how the e-participation project affects local democracy by changing existing practices and using them as new instruments to achieve local democracy. In order to identify in detail the attitudes of individuals in hypothetical scenarios (i.e. for the sub-sample that includes people who have not used the platform), we have included contingent valuation methods (see, for example, Hoevenagel, 1994). Using this method borrowed from psychology, we attempt to assess the typical attitudes and behaviours of individuals in the event that they actually used the platform during the pilot phase. For example, the use of photos of the platform during the interview allowed the interviewees who had not used the platform to be "mentally immersed" in the studied context. The questionnaire employed is as follows: 
1. What do you think is the sense and purpose of citizen participation in political debate in general?

2. To what extent do you feel affected by the issues discussed (participation in direct democracy)?

3. Do you have the impression that the cantonal constitution has an influence on your everyday political, economic or social life?

a. How do you assess the Cantonal Constitution in relation to the Federal Constitution?

b. Did you take part in the vote to elect the candidates for the Constituent Assembly?

4. What is your preferred way of expressing your opinion in today's politics?

5. How do you assess digital technologies in relation to the democratic process in Switzerland?

6. What types of technologies do you think could be useful to involve you more in a political debate?

(Here the interviewer shows to the interviewee the photo of the homepage of the citizens' discussion platform and explain its features in a few words)

7. What are the benefits you perceive when using an online citizens' discussion platform such as this one?

9. Does the quality of the user interface influence your decisions when using these new technologies

10. Do you think that the platform for citizen participation has a real influence on the definition of the new Cantonal Constitution?

11. What advantages or drawbacks do you think there are in using a platform to express your opinion on political issues instead of using other methods such as meetings or political campaigns?

12. Would you be willing to invest time to use such platforms?

13. Do you think that a digitalized citizen consultation platform can bring new democratic opportunities into the political decision-making process?

14. Do you think that an online political platform can promote political commitment?

This short paper is based on the 20 interviews conducted with Valais citizens (users and non-users of the platform and stakeholders) and expatriates living in Valais. The questionnaire administered to those who have used the platform also contains an additional series of questions of the UX type (i.e. User Experience) in order to collect data on the interactional aspects between the platform site and its users.

In addition to the field survey, we conducted a netnography based on the content left by the users of the electronic platform. Netnography (Kozinets, 2007) represents an online research method that has its origin in ethnography. This method tries to understand social interaction in the framework of digital media. We have used it here not to analyze the meaning of the content present online, but rather to understand the why and how of this new way of "practicing" e-participation. 1235 contents of the electronic platform (valaisdemain.ch in French and wallismorgen.ch in German) have been analysed according to this approach.

\section{RESULTS AND DISCUSSION}

In this section, we present the general synthesis of the results. What emerges from our interview transcripts represents elements of perception evoked by people involved and/or interested in Valais politics. In general, they point out that participatory e-democracy in Valais entered politics with the creation of such a digital platform for citizen participation. This initiative, within the framework of large-scale projects such as the renewal of the Constitution, is intended to give greater attention to public opinion. The citizens' consultation platform is seen as a positive element in the democratic process because it leads some citizens to see all the questions asked differently than in the tabloid press. Thus, the platform is not linked to emotionally charged news or hot topics. Citizens have the right to be informed about political debates. They have the right to agree or disagree, but they do not have the right not to know. Moreover, this platform provides clear and authentic information in general, avoiding false news. The platform serves to change the way citizens participate, which could possibly change the political structure in general. It mobilises the grassroots and contributes to political commitment. A democracy works well if many more people speak out. However, this process must remain in the hands of the state because it is the guarantor of the citizens. The citizens' consultation platform also needs to address some democratic deficits in the policy-making process, as it currently seems to have too limited a role in decision-making, especially with regard to the total revision of the cantonal constitution. Citizens exercise an informational influence by having had the opportunity to make their interests and preferences known to the public authorities. This limitation can only be seen as a façade to make citizens believe that their opinion has been taken into account. 
The results of this research also show that UX-related variables ("User Experience"), such as perceived usefulness, perceived ease of use, perceived effort required and perceived trust, have a significant direct effect on the behavioural intention of citizens to use such a platform. Again, all agree that, although they welcome a first in terms of e-participation, a major development needs to be undertaken to have a real driving effect on citizens' political engagement over time. Indeed, as discussed in the section on literature review, research indicates that perceived trust and the usefulness of the technology are the key factors in getting people's intention to use this participatory platform.

The netnographic analysis confirms to some extent the findings of the field analysis presented above. An elaborate construction is immediately noticeable in both the proposals and the feedback comments filed on the platform. On the platform, the emotional element is little present as it is normally the case in most social networks. Respect is the order of the day and even if there are opposing points of view, there is a kind of convergent search for the appropriate phrase or expression. Most people come up with short, simple statements. Reactions for or against also get to the heart of the matter and always provide a very relevant justification. There is never an attack on the person. Negative reactions are only directed at the text. There are very few polemical arguments. We can therefore see that the platform's design has worked well in terms of generating and exchanging ideas, but the people who participate in it necessarily have an intimate knowledge of the Valais political system. One also perceives a willingness on the part of people to explore new paths, radical changes, combined with a strong attachment to symbols such as the flag or the reference to God for example. All the subjects of the constitution, classified into ten main themes, are addressed. There are no neglected subjects, nor over-treated subjects. This follows somewhat the logic of an encyclopaedic construction of knowledge (analogy to d'Alembert's encyclopaedia). It is as if each empty sub-category had been filled in by a scholar. This discovery came as a surprise. So we can see that the primary objective, which was to encourage people to give ideas, is not necessarily achieved, even though in the field study, people who did not use the platform saw an interest in strengthening democracy. Many improvements and tests on a UX basis will certainly be necessary to achieve this primary objective. On the other hand, the good surprise already mentioned above in this first pilot project is that this platform brings a high quality and very exhaustive content that should help the 130 Constituents to realize their project.

It is clear that the four-phase learning process (Collan and Tétard, 2011) illustrates something that so many people overlook: the fact that there are significant levels of user involvement and effort required. Knowledge of these phases helps to create methods that provide a good balance between user-friendly features or functions and the robustness of the information.

This platform is one tool among others, but it can be an effective channel of communication between citizens and government, allowing a multidirectional flow of information, with significant interaction or decisive influence.

Such an approach must indeed involve social science experts. Social sciences can integrate genuine scientific and philosophical reflection in this process towards better integration, acceptance and use.

\section{CONCLUSION}

Changing the involvement of citizens in their democratic practice is no small task in the age of digitisation. In the Swiss canton of Valais, the people have voted for a complete revision of their constitution. This change is carried out through a process called the constituent process, in which 130 citizens were elected to carry out the lengthy revision work before the final text is again voted on by the people to approve it. For two months from 7 November to 5 January 2020, a pilot project for a digital platform for citizens was set up so that everyone in the Canton could put forward ideas for the new constitution. These proposals were public and everyone could then react with a comment and/or a vote. As part of this pilot experiment, we conducted semi-directive interviews with the inhabitants of the canton in order to better know and understand their perception of this approach to e-democracy. Parallel to this field survey, we also carried out a "netnography" on the basis of the proposals and comments submitted on the platform not in order to study their semantic content, but rather to understand what was changing in the way people interact in the democratic debate from the moment they joined an e-participation process. Most respondents see this development of e-democracy in a positive light. On the other hand, they think that the tool is not mature enough to attract people who are still not very involved in politics, such as young people. The netnography carried out confirms these assertions since the analysis of the 
comments shows that the people who produced the content are all well written, directly adopt the "tone" of a constitution and demonstrate a high level of political literacy. The next step in this research will be to provide recommendations using service and UX techniques to improve the quality of the "citizen's journey" in terms of their involvement in democratic processes.

\section{REFERENCES}

Almarashdeh, I. and Alsmadi, M.K., 2017. How to make them use it? Citizens acceptance of M-government. Applied Computing and Informatics, 13(2), pp.194-199.

Callon, M., 1999. Actor-network theory—the market test. The Sociological Review, 47(1_suppl), pp.181-195.

Collan, M. and Tétard, F., 2011, August. Lazy User Model: solution selection and discussion about switching costs. In Scandinavian conference on information systems (pp. 56-68). Springer, Berlin, Heidelberg.

Davis, F.D., 1989. Perceived usefulness, perceived ease of use, and user acceptance of information technology. MIS quarterly, pp.319-340.

Fung, A., 2006. Varieties of participation in complex governance. Public administration review, 66, pp.66-75.

Ghauri, P.N. and Grønhaug, K., 2005. Research methods in business studies: A practical guide. Pearson Education.

Hoevenagel, R., 1994. An assessment of the contingent valuation method. In Valuing the environment: methodological and measurement issues (pp. 195-227). Springer, Dordrecht.

Kozinets, R.V., 2007. Netnography. The Blackwell Encyclopedia of Sociology, pp. 1-2.

Macintosh, A. and Whyte, A., 2008. Towards an evaluation framework for eParticipation. Transforming government: People, process and policy, 2(1), pp.16-30.

Przeworski, A., Stokes, S.C. and Manin, B. eds., 1999. Democracy, accountability, and representation (Vol. 2). Cambridge University Press.

Taherdoost, H., 2018. A review of technology acceptance and adoption models and theories. Procedia Manufacturing, 22, pp.960-967.

Venkatesh, V. and Davis, F.D., 2000. A theoretical extension of the technology acceptance model: Four longitudinal field studies. Management science, 46(2), pp.186-204.

Venkatesh, V., Morris, M.G., Davis, G.B. and Davis, F.D., 2003. User acceptance of information technology: Toward a unified view. MIS quarterly, pp.425-478. 